\title{
Treatment failure of pharyngeal gonorrhoea with internationally recommended first-line ceftriaxone verified in Slovenia, September 2011
}

M Unemo (magnus.unemo@orebroll.se) ${ }^{1}$, D Golparian¹, M Potočnik ${ }^{2}$, S Jeverica $^{3}$

1. World Health Organization Collaborating Centre for Gonorrhoea and other Sexually Transmitted Infections, Swedish Reference Laboratory for Pathogenic Neisseria, Department of Laboratory Medicine, Microbiology, Örebro University Hospital, Örebro, Sweden

2. Department of Dermatovenereology, University Medical Centre Ljubljana, Ljubljana, Slovenia

3. Institute of Microbiology and Immunology, Faculty of Medicine, University of Ljubljana, Ljubljana, Slovenia

Unemo M, Golparian D, Potočnik M, Jeverica S. Treatment failure of pharyngeal gonorrhoea with internationally recommended first-line ceftriaxone verified in Slovenia, September 2011. Euro Surveill. 2012;17(25):pii=20200. Available online: http://www.eurosurveillance.org/ViewArticle.aspx?Articleld=20200

We describe the second case in Europe of verified treatment failure of pharyngeal gonorrhoea, caused by an internationally occurring multidrug-resistant gonococcal clone, with recommended first-line ceftriaxone $250 \mathrm{mg}$ in Slovenia. This is of grave concern since ceftriaxone is last remaining option for empirical treatment. Increased awareness of ceftriaxone failures, more frequent test-of-cure, strict adherence to regularly updated treatment guidelines, and thorough verification/falsification of suspected treatment failures are essential globally. New effective treatment options are imperative.

\section{Background}

Neisseria gonorrhoeae has developed resistance to all antimicrobial drugs previously used as first-line treatment for gonorrhoea [1]. Resistance to currently recommended first-line third-generation cephalosporins - cefixime and ceftriaxone - is emerging [1-3], and treatment failures with cefixime have been verified in Japan [4] and several European countries, namely Norway [5], the United Kingdom [6], Austria [7] and France [8]. One failure to treat pharyngeal gonorrhoea with ceftriaxone, the last remaining option for empiric treatment, has also been verified in Europe (Sweden) [9]. It is likely that treatment failures with ceftriaxone will initially accumulate for pharyngeal gonorrhoea because these infections are harder to treat than urogenital infections $[1,10,11]$. It is of grave concern that during the past year, the first three extensively drugresistant (XDR) [1] N. gonorrhoeae strains that also had high-level ceftriaxone resistance were reported from Japan, France and Spain $[8,12,13]$.

In this emergent situation of fear that gonorrhoea may become untreatable $[1,8,12]$, the European Centre for Disease Prevention and Control (ECDC) has prepared a response plan for the European Union [14]. The World Health Organization (WHO) has published the
'Global Action Plan to Control the Spread and Impact of Antimicrobial Resistance in Neisseria gonorrhoeae' [15].

This report describes a ceftriaxone treatment failure of pharyngeal gonorrhoea in Slovenia in 2011, which is the second one strictly verified in Europe (and possibly globally).

\section{Case description}

In early September 2011, a Slovenian bisexual woman in her early 305 visited a dermatovenereologist in Ljubljana, Slovenia (Day 1). She had no symptoms of gonorrhoea, however, she was sampled and administered the internationally recommended first-line treatment of $1 \times 250 \mathrm{mg}$ ceftriaxone intramuscularly (Table), based on the fact that she had had unprotected oral and vaginal sex with gonorrhoea-positive casual male partner in late August 2011 in Belgrade, Serbia. The partner could later not be traced in Serbia.

Microscopy of Gram-stained smear of a cervical specimen was negative for $N$. gonorrhoeae. However, two days later (Day 3), a pharyngeal culture was shown to be positive for $N$. gonorrhoeae, while the cervical culture was negative. Chlamydia trachomatis DNA was identified in an additional cervical sample, using the COBAS TaqMan CT Test v2.o (Roche Diagnostics). During a follow-up visit seven days after the initial visit (Day 8), a test-of-cure (TOC) pharyngeal culture was taken and examination showed no signs or symptoms of pharyngeal gonorrhoea, and she was given doxycycline at a dosage of $100 \mathrm{mg}$ twice a day, for seven days, for a concomitant chlamydial infection. However, two days later (Day 10) the TOC culture confirmed gonococci in a pharyngeal sample. About three weeks later (Day 30), the patient returned with symptoms of acute pharyngitis (pain, inflammation and fever) and was given one dose of $250 \mathrm{mg}$ ceftriaxone intramuscularly and 
one oral dose of $1 \mathrm{~g}$ azithromycin. Finally, a follow-up examination after about four months (Day 173) showed no signs of infection, and a pharyngeal TOC culture was negative for $N$. gonorrhoeae (Table). The patient repeatedly reassured that she had not had any sexual contacts between the ceftriaxone therapy and the TOC.

\section{Characterisation of $N$. gonorrhoeae isolates}

The pre- and post-treatment $N$. gonorrhoeae isolates were species-confirmed by sugar utilisation test and Phadebact Monoclonal GC Test (Pharmacia Diagnostics). The isolates were indistinguishable using serovar determination (Bpyut), full-length porB gene sequencing, multilocus sequence typing (MLST; ST1901 [12]), and N. gonorrhoeae multiantigen sequence typing (NG-MAST; ST1407 [16]). Using Etest (AB bioMérieux), both isolates showed a ceftriaxone minimum inhibitory concentration (MIC) of $0.125 \mathrm{mg} / \mathrm{L}$ (Table), and overall indistinguishable antibiograms (cefixime $0.25 \mathrm{mg} / \mathrm{L}$, spectinomycin $16 \mathrm{mg} / \mathrm{L}$, azithromycin 0.5 $\mathrm{mg} / \mathrm{L}$, and ciprofloxacin $>32 \mathrm{mg} / \mathrm{L}$ ) and were beta-lactamase-negative. According to the European Committee on Antimicrobial Susceptibility Testing (EUCAST) [17], the MIC of ceftriaxone for these isolates were equal to the resistance breakpoint $(>0.125 \mathrm{mg} / \mathrm{L})$. Sequencing of resistance determinants for third-generation cephalosporins $[1,8,12,18,19]$ showed that both isolates contained an identical penA mosaic allele XXXIV [12], which has been correlated with decreased susceptibility or resistance to third-generation cephalosporins and treatment failure with cefixime $[5,20,21]$. In addition, they contained $m t r R$ and pen $B$ alterations that further increase the MICs of third-generation cephalosporins $[1,8,12,19]$.

\section{Discussion}

This study describes the second verified case in Europe (possibly globally) of treatment failure of pharyngeal gonorrhoea with the internationally recommended firstline treatment of $250 \mathrm{mg}$ ceftriaxone, the last remaining treatment option. The failure was strictly verified in accordance with WHO recommendations [1,15], i.e. detailed clinical records were obtained, reinfection was excluded as much as possible, pre- and posttreatment isolates were indistinguishable using highly discriminatory typing, ceftriaxone MICs were elevated, and the isolates contained well-known cephalosporin resistance determinants. The reporting of the case was unfortunately delayed because it took several months before the patient returned for follow-up examination and TOC after the third antimicrobial treatment (to prove successful eradication of infections).

This case shows that ceftriaxone at a dosage of $1 \times 250$ $\mathrm{mg}$ may in rare cases not be enough for treatment of pharyngeal gonorrhoea caused by gonococcal strains with ceftriaxone MICs of $0.125 \mathrm{mg} / \mathrm{L}$. A $250 \mathrm{mg}$ ceftriaxone dose also results in median times of free ceftriaxone above the MIC of only $24.1 \mathrm{~h}$ (range: $10.5-52.2 \mathrm{~h}$ ) for the detected MIC of $0.125 \mathrm{mg} / \mathrm{L}$ [22], and rare treatment failures may happen in the lower range. Nevertheless, these cases are likely to be treatable with enhanced ceftriaxone doses or dual antimicrobial treatment that has already been introduced as first-line empiric treatment in the United States [10] and the United Kingdom [23]. It may be crucial to promptly revise also other national and regional treatment guidelines, and a revision of the European guidelines from the International Union against Sexually Transmitted Infections (IUSTI) and WHO [2] are currently in progress.

\section{TABLE}

Details of verified ceftriaxone treatment failure of one case of Neisseria gonorrhoeae pharyngeal infection, Slovenia, September 2011

\begin{tabular}{|c|c|c|c|c|c|c|c|c|}
\hline $\begin{array}{l}\text { Age } \\
\text { (years)/ } \\
\text { Sex }\end{array}$ & $\begin{array}{l}\text { Place of } \\
\text { exposure }\end{array}$ & $\begin{array}{c}\text { Healthcare clinic } \\
\text { (day of } \\
\text { presentation) }\end{array}$ & $\begin{array}{l}\text { Symptoms } \\
\text { (signs) }\end{array}$ & $\begin{array}{c}\text { Positive } \\
\text { diagnostics }\end{array}$ & $\begin{array}{c}\text { Negative } \\
\text { diagnostics }\end{array}$ & $\begin{array}{l}\text { MIC (mg/L) } \\
\text { Ceftriaxone }\end{array}$ & $\begin{array}{c}\text { MLST } \\
(\text { NG-MAST)a }\end{array}$ & Treatment \\
\hline \multirow{4}{*}{$\begin{array}{l}32 / \\
\text { female }\end{array}$} & \multirow{4}{*}{$\begin{array}{c}\text { Serbia } \\
\text { (Belgrade) }\end{array}$} & STD (1) & $(-)$ & $\begin{array}{c}\text { GC culture } \\
\text { (pharynx) and } \\
\text { CT PCR (cervix) }\end{array}$ & $\begin{array}{l}\text { GC culture } \\
\text { (cervix) and } \\
\text { microscopy } \\
\text { (cervix) }\end{array}$ & 0.125 & $\begin{array}{l}\text { ST1901 } \\
\text { (ST1407) }\end{array}$ & $\begin{array}{c}\text { Ceftriaxone } 250 \\
\mathrm{mg} \times 1 \mathrm{IM}\end{array}$ \\
\hline & & STD (8) & $(-)$ & $\begin{array}{l}\text { GC culture } \\
\text { (pharynx) }\end{array}$ & NA & 0.125 & $\begin{array}{l}\mathrm{ST} 1901 \\
(\mathrm{ST} 1407)\end{array}$ & $\begin{array}{l}\text { Doxycycline } 100 \\
\text { mg b.i.d., } 7 \text { days } \\
\text { PO }^{\mathrm{b}}\end{array}$ \\
\hline & & STD (30) & $\begin{array}{l}\text { Pharyngitis } \\
\text { (inflammation } \\
\text { in pharynx) }\end{array}$ & NA & NA & NA & NA & $\begin{array}{l}\text { Ceftriaxone } 250 \\
\text { mgx1 IM and } \\
\text { azithromycin } 1 \\
\text { gx1 PO }\end{array}$ \\
\hline & & STD (173) & $(-)$ & NA & $\begin{array}{c}\text { GC culture } \\
\text { (pharynx), CT } \\
\text { PCR (cervix) }\end{array}$ & NA & NA & NA \\
\hline
\end{tabular}

b.i.d.: twice a day; CT: Chlamydia trachomatis; GC: Neisseria gonorrhoeae; IM: intramuscular administration; MIC: minimum inhibitory concentration; MLST: multilocus sequence typing; NA: not applicable; NG-MAST: Neisseria gonorrhoeae multi-antigen sequence typing; PCR: polymerase chain reaction; PO: per oral administration; STD: sexually transmitted diseases.

a MIC (mg/L) as determined by Etest, MLST [12] and NG-MAST [16] of N. gonorrhoeae pre- and post-treatment isolates.

b Treatment of concomitant C. trachomatis infection. 
It is worrying that the gonococcus causing this treatment failure was assigned to MLST ST1901 and NG-MAST ST1407, which is a multidrug-resistant gonococcal clone that also shows decreased susceptibility and resistance to cefixime and is spreading worldwide $[5,7,8,13,20,21,24-28]$. The previously reported treatment failures with cefixime in Norway [5], Austria [7], France [8] and likely in the United Kingdom [6], were caused by this gonococcal clone or its evolving subtypes. This clone has also shown its capacity to develop high-level resistance to ceftriaxone $[8,13]$.

In conclusion, the second case in Europe (possibly worldwide) of clinical failure using standard ceftriaxone treatment for pharyngeal gonorrhoea, caused by an internationally occurring multidrug-resistant gonococcal clone, has been strictly verified in Slovenia. An increased awareness of treatment failures with ceftriaxone, more frequent TOC (all cases of pharyngeal cases may be crucial), strict adherence to appropriate treatment guidelines, which need to be regularly updated based on antimicrobial resistance surveillance data, and thorough verification/falsification of suspected treatment failures (including subsequent tracing of sexual contacts of the index case with the treatment failure) are essential globally. A stronger focus on pharyngeal gonorrhoea, including increased sampling of pharyngeal specimens and promotion of condom use also when practising oral sex, is also crucial because pharyngeal infection is harder to treat than urogenital infection, relatively common, and is frequently an asymptomatic reservoir for infection and emergence of resistances $[1,5]$. Ultimately, new options for effective treatment of gonorrhoea are imperative.
References

1. Tapsall JW, Ndowa F, Lewis DA, Unemo M. Meeting the public health challenge of multidrug- and extensively drugresistant Neisseria gonorrhoeae. Expert Rev Anti Infect Ther. 2009;7(7):821-34.

2. Bignell C, IUSTI/WHO. 2009 European (IUSTI/WHO) guideline on the diagnosis and treatment of gonorrhoea in adults. Int J STD AIDS. 2009;20(7):453-7.

3. Cole MJ, Unemo M, Hoffmann S, Chisholm SA, Ison CA, van de Laar MJ. The European gonococcal antimicrobial surveillance programme, 2009. Euro Surveill. 2011;16(42):pii=19995. Available from: http://www.eurosurveillance.org/ViewArticle. aspx?Articleld $=19995$

4. Yokoi S, Deguchi T, Ozawa T, Yasuda M, Ito S, Kubota Y, et al. Threat to cefixime treatment of gonorrhea. Emerg Infect Dis. 2007;13(8):1275-7.

5. Unemo M, Golparian D, Syversen G, Vestrheim DF, Moi H. Two cases of verified clinical failures using internationally recommended first-line cefixime for gonorrhoea treatment, Norway, 2010. Euro Surveill. 2010;15(47):pii=19721. Available from: http://www.eurosurveillance.org/ViewArticle. aspx?Articleld $=19721$

6. Ison CA, Hussey J, Sankar KN, Evans J, Alexander S. Gonorrhoea treatment failures to cefixime and azithromycin in England, 2010. Euro Surveill. 2011;16(14):pii:19833. Available from: http://www.eurosurveillance.org/ViewArticle. aspx?Articleld $=19833$

7. Unemo M, Golparian D, Stary A, Eigentler A. First Neisseria gonorrhoeae strain with resistance to cefixime causing gonorrhoea treatment failure in Austria. Euro Surveill. 2011;16(43):pii=19998. Available from: http://www. eurosurveillance.org/ViewArticle.aspx?Articleld=19998

8. Unemo M, Golparian D, Nicholas R, Ohnishi M, Gallay A, Sednaoui P. High-level cefixime- and ceftriaxone-resistant N. gonorrhoeae in France: novel penA mosaic allele in a successful international clone causes treatment failure. Antimicrob Agents Chemother. 2012;56(3):1273-80.

9. Unemo M, Golparian D, Hestner A. Ceftriaxone treatment failure of pharyngeal gonorrhoea verified by international recommendations, Sweden, July 2010. Euro Surveill. 2011;16(6):pii=19792. Available from: http://www. eurosurveillance.org/ViewArticle.aspx?Articleld=19792

10. Workowski KA, Berman S, Centers for Disease Control and Prevention (CDC). Sexually transmitted diseases treatment guidelines, 2010. MMWR Recomm Rep. 2010;59(RR-12):1-110.

11. Moran JS. Treating uncomplicated Neisseria gonorrhoeae infections: is the anatomic site of infection important? Sex Transm Dis. 1995;22(1):39-47.

12. Ohnishi M, Golparian D, Shimuta K, Saika T, Hoshina S, Iwasaku K, et al. Is Neisseria gonorrhoeae initiating a future era of untreatable gonorrhea?: detailed characterization of the first strain with high-level resistance to ceftriaxone. Antimicrob Agents Chemother. 2011;55(7):3538-45.

13. Cámara J, Serra J, Ayats J, Bastida T, Carnicer-Pont D, Andreu A, et al. Molecular characterization of two high-level ceftriaxoneresistant Neisseria gonorrhoeae isolates detected in Catalonia, Spain. J Antimicrob Chemother. 2012 May 7. [Epub ahead of print].

14. European Centre for Disease Prevention and Control (ECDC). Response plan to control and manage the threat of multidrugresistant gonorrhoea in Europe. Stockholm: ECDC; 2012. p. 1-23. Available from: http://www.ecdc.europa.eu/en/ publications/Publications/1206-ECDC-MDR-gonorrhoearesponse-plan.pdf

15. World Health Organization (WHO), Department of Reproductive Health and Research. Global Action Plan to Control the Spread and Impact of Antimicrobial Resistance in Neisseria gonorrhoeae. Geneva: WHO; 2012. p. 1-36. Available from: http://www.who.int/reproductivehealth/publications/ rtis/9789241503501

16. Unemo M, Sjöstrand A, Akhras M, Gharizadeh B, Lindbäck E, Pourmand N, et al. Molecular characterization of Neisseria gonorrhoeae identifies transmission and resistance of one ciprofloxacin-resistant strain. APMIS. 2007;115(3):231-41.

17. European Committee on Antimicrobial Susceptibility Testing (EUCAST). Breakpoint tables for interpretation of MICs and zone diameters. Version 2.0. Basel: European Society of Clinical Microbiology and Infectious Diseases; 1 Jan 2012. Available from: http://www.eucast.org/fileadmin/src/ media/PDFs/EUCAST_files/Breakpoint_tables/Breakpoint table_v_2.0_120221.pdf

18. Unemo M, Fasth O, Fredlund H, Limnios A, Tapsall J. Phenotypic and genetic characterization of the 2008 WHO Neisseria gonorrhoeae reference strain panel intended for global quality assurance and quality control of gonococcal antimicrobial 
resistance surveillance for public health purposes. J Antimicrob Chemother. 2009;63(6):1142-51.

19. Zhao S, Duncan M, Tomberg J, Davies C, Unemo M, Nicholas R. Genetics of chromosomally mediated intermediate resistance to ceftriaxone and cefixime in Neisseria gonorrhoeae.

Antimicrob Agents Chemother. 2009;53(9):3744-51.

20. Buono S, Wu A, Hess DC, Carlson IS, Rauch L, Philip SS, et al. Using the Neisseria gonorrhoeae Multiantigen SequenceTyping Method to Assess Strain Diversity and Antibiotic Resistance in San Francisco, California. Microb Drug Resist. 2012 Jun 11. [Epub ahead of print].

21. Heymans R, Bruisten SM, Golparian D, Unemo M, de Vries HJ, van Dam AP. Clonally related Neisseria gonorrhoeae isolates with decreased susceptibility to the extended-spectrum cephalosporin cefotaxime in Amsterdam, the Netherlands. Antimicrob Agents Chemother. 2012;56(3):1516-22.

22. Chisholm SA, Mouton JW, Lewis DA, Nichols T, Ison CA, Livermore DM. Cephalosporin MIC creep among gonococci: time for a pharmacodynamic rethink? J Antimicrob Chemother. 2010;65(10):2141-8

23. Bignell C, Fitzgerald M; Guideline Development Group. UK national guideline for the management of gonorrhoea in adults, 2011. Int J STD AIDS. 2011;22(10):541-7.

24. Golparian D, Hellmark B, Fredlund H, Unemo M. Emergence, spread and characteristics of Neisseria gonorrhoeae isolates with in vitro decreased susceptibility and resistance to extended-spectrum cephalosporins in Sweden. Sex Transm Infect. 2010;86(6):454-60.

25. Pandori M, Barry PM, Wu A, Ren A, Whittington WL, Liska $\mathrm{S}$, et al. Mosaic penicillin-binding protein 2 in Neisseria gonorrhoeae isolates collected in 2008 in San Francisco, California. Antimicrob Agents Chemother. 2009;53(9);4032-4.

26. Tapsall JW, Ray S, Limnios A. Characteristics and population dynamics of mosaic penA allele-containing Neisseria gonorrhoeae isolates collected in Sydney, Australia, in 20072008. Antimicrob Agents Chemother. 2010;54(1):554-6.

27. Tanaka M, Koga Y, Nakayama H, Kanayama A, Kobayashi I, Saika T, et al. Antibiotic-resistant phenotypes and genotypes of Neisseria gonorrhoeae isolates in Japan: identification of strain clusters with multidrug-resistant phenotypes. Sex Transm Dis. 2011;38(9):871-5.

28. Neisseria gonorrhoeae Multi Antigen Sequence Typing (NGMAST). Query global sequence and ST database. London: Department of Infectious Disease Epidemiology, Imperial College London and are funded by The Wellcome Trust. Available from: http://www.ng-mast.net/sql/allelicprofile.asp. 